\title{
O LAZER NAS DIFERENTES FASES DA VIDA DE CENTENÁRIOS
}

Recebido em: 19/03/2016

Aceito em: 22/11/2016

Maíra Naman
Inês Amanda Streit
Artur Rodrigues Fortunato
Alcyane Marinho
Giovana Zarpellon Mazo
Universidade do Estado de Santa Catarina - UDESC
Florianópolis - SC - Brasil

RESUMO: O objetivo desse estudo é analisar o lazer nas diferentes fases da vida de centenários. Trata-se de um estudo de natureza qualitativa e teve como participantes seis centenários $(102,83 \pm 1,6)$ e seus respectivos cuidadores. $\mathrm{O}$ grupo foi selecionado a partir dos critérios de inclusão: ter idade igual ou superior a cem anos comprovada por documento, ter condições cognitivas preservadas e residir nos municípios da mesorregião Grande Florianópolis (SC). O instrumento utilizado foi o Protocolo de Avaliação Multidimensional do Idoso Centenário, sendo utilizados os Blocos 1, 3, 4 e 5. Os dados foram analisados por meio da análise de conteúdo. Com relação às atividades realizadas no lazer, na infância as mais citadas envolviam movimento e na adolescência, destacaram-se as atividades sociais. $\mathrm{Na}$ fase adulta foram citadas atividades das categorias artística, social e turística, e, por sua vez, na velhice e na fase atual, observou-se a manutenção das atividades turísticas, ressaltando que, no decorrer da vida, observou-se uma diminuição considerável no lazer em todas as categorias.

PALAVRAS CHAVE: Atividades de Lazer. Estágios do Ciclo de vida. Idoso de 80 Anos ou mais.

\section{LEISURE AT DIFFERENT STAGES OF LIFE OF CENTENARIANS}

ABSTRACT: The aim of this study is to analyze the leisure in the different stages of life of centenarians. This is a qualitative study and the participants were six centenarians $(102,83 \pm 1,6)$ and their caregivers. The group was selected from the inclusion criteria: age over than one hundred years attested by a document, have preserved cognitive conditions and reside in the municipalities of mesoregion Florianopolis (SC). The instrument used was the Multidimensional Assessment Protocol Elderly Centenarian, being used Blocks 1, 3, 4 and 5. The data were analyzed using content analysis. Regarding the activities at leisure in the most cited infancy and adolescence involved movement, stood out social activities. In adulthood were mentioned activities of artistic categories, social and tourism, and, in turn, in old age and in the current phase, there was the maintenance of tourist activities, emphasizing that in the course of life, we observed a considerable decrease leisure in all categories. 
KEYWORDS: Leisure Activities. Life Cycle Stages. Aged 80 and over.

\section{Introdução}

Mundialmente, a transição demográfica evidencia um aumento significativo do segmento populacional idoso, crescimento que também influencia no acréscimo do número de pessoas com cem anos ou mais de idade (WHO, 2015), que, de acordo com a United Nations (2015), atingiu 451 mil centenários em 2015. No Brasil, o último censo demográfico identificou 24.236 indivíduos nessa faixa etária, e, desses, 405 encontravam-se no estado de Santa Catarina (IBGE, 2010).

Os centenários são exemplos importantes do envelhecimento bem-sucedido, no que diz respeito aos aspectos biológico, funcional, social e comportamental, havendo um interesse dos pesquisadores em investigar esse grupo etário e os fatores que levam à longevidade (JANNEY et al., 2010). Dentre os aspectos relacionados à longevidade, destaca-se a prática de atividades no lazer. Estudo de Zhang (2006), com idosos chineses de 80 a 105 anos que realizavam atividades no lazer como jardinagem, jogos, assistir televisão e ouvir rádio, verificaram menor comprometimento cognitivo e redução do risco de morte. Outros estudos, por sua vez, verificaram associação da prática regular de atividades no lazer a um menor risco de demência na longevidade (SCARMEAS et al., 2001; WANG et al., 2013).

Nessa perspectiva, resultados de uma revisão sistemática mostraram efeitos positivos da prática das atividades no lazer no envelhecimento, principalmente sobre a mortalidade, a capacidade funcional, o estado cognitivo e o bem-estar (DIAS, DUARTE; LEBRÃO, 2010) e a qualidade de vida (SANTOS et al., 2014). Ao analisar estudos sobre atividades no lazer realizadas pelos centenários, observa-se que estes são 
escassos e pontuais. Como exemplo, o estudo de Schrader (2008) com 454 centenários americanos, mostrou que as principais atividades no lazer que eles praticavam eram artesanato, jardinagem, leitura e escrita, jogos de cartas, interação social, entre outros, proporcionando, de acordo com a fala dos centenários, melhora na qualidade de vida por meio do engajamento social.

Também no Brasil os estudos voltados à temática de atividades no lazer praticadas por centenários são escassos. Verifica-se o estudo de Longarai (2005) que identificou a relação entre os hábitos de atividade física pregressa e as atividades da vida diária em nonagenários e centenários e apontou que, mesmo sem a prática de atividade física regular, os idosos mantinham-se ativos por meio de suas atividades ocupacionais e no lazer. Estudos envolvendo apenas centenários verificaram que as atividades no lazer praticadas ocorrem predominantemente no ambiente domiciliar como assistir televisão, dormir e receber visitas e aqueles que praticavam as atividades sociais no lazer como "fazer compras" e "visitar parentes e amigos" apresentaram melhor nível de atividade física (BENETTI, 2011; STREIT, 2013).

Desse modo, observa-se a necessidade de investigações sobre as atividades no lazer realizadas nas diferentes fases da vida dos centenários. Estudo de Gomes (2014) realizou discussão sobre as abordagens teórico-conceituais do lazer e observou que é considerado hegemônico o entendimento do lazer como contraponto do trabalho. A autora destaca que o lazer é uma prática social complexa que abarca uma multiplicidade de vivências culturais lúdicas contextualizadas e historicamente situadas.

Desta forma, este artigo compartilha as ideias de Gomes (2014) e, na tentativa de compreender as formas de manifestações culturais de centenários, embasou-se 
metodologicamente na proposta de conteúdos culturais proposta por Dumazedier (1973) e complementada por Camargo (1998).

A expressão conteúdos culturais diferencia cinco áreas de interesses verificados no lazer (físicos, manuais, artísticos, intelectuais e sociais). A distinção entre tais conteúdos só pode se estabelecer em termos de predominância e representando escolhas subjetivas, uma vez que se constituem em um todo interligado e não em esferas estanques, como enfatiza Marcellino (2007).

Assim, acredita-se que o conhecimento sobre as diferentes formas pregressas de atividades no lazer dos centenários pode fornecer parâmetros para entender as atuais atividades e, com isso, propor intervenções capazes de suprir as diferentes demandas desta população, uma vez que, segundo Benetti (2011) e Streit (2013), a maioria das atividades no lazer restringe-se a iniciativas passivas e restritas ao ambiente domiciliar.

Essa temática é de suma importância para compreender o processo de longevidade, as características de idosos em idade muito avançada e seu estilo de vida. Diante disso, tem-se como objetivo do estudo analisar as atividades no lazer nas diferentes fases da vida de idosos centenários.

\section{Método}

Esse estudo faz parte da pesquisa "SC100: Estudo Multidimensional dos Centenários de Santa Catarina”, que utiliza o Protocolo de Avaliação Multidimensional do Idoso Centenário, elaborado pelo Laboratório de Gerontologia (LAGER) do Centro de Ciências de Saúde e do Esporte (CEFID) da Universidade do Estado de Santa Catarina (UDESC) (LAGER, 2015). A pesquisa foi conduzida de acordo com padrões éticos contidos na Resolução 466/2012 e aprovada pelo Comitê de Ética em Pesquisas 
em Seres Humanos da Universidade do Estado de Santa Catarina, sob o parecer $560.107 / 2014$.

Este estudo de natureza qualitativa (MINAYO, 2008) teve como participantes seis idosos centenários $(102,8 \pm 1,6)$ e seus respectivos cuidadores. O grupo foi selecionado a partir dos critérios de inclusão: ter idade igual ou superior a cem anos comprovada por documento, ter condições cognitivas preservadas e residir nos municípios da mesorregião Grande Florianópolis (SC).

Como instrumento de coleta de dados utilizou-se parte específica do Protocolo de Avaliação Multidisciplinar do Idoso Centenário (LAGER, 2015). No Quadro1 apresentam-se as variáveis do instrumento citado que foram utilizadas nesse estudo.

Quadro 1 - Blocos utilizados do Protocolo Aplicado ao Idoso Centenário.

\begin{tabular}{|c|c|c|c|}
\hline BLOCOS & OBJETIVO/VARIÁVEIS & INSTRUMENTO & REFERENCIA \\
\hline $\begin{array}{c}\text { Bloco 01 - Identificação } \\
\text { do Idoso }\end{array}$ & $\begin{array}{c}\text { Nome, data de nascimento, } \\
\text { idade, sexo, documento } \\
\text { comprobatório }\end{array}$ & Ficha Diagnóstica & (LAGER/CEFID/UDESC) \\
$\begin{array}{c}\text { Bloco 03 - Saúde } \\
\text { Mental do Idoso }\end{array}$ & $\begin{array}{c}\text { Avaliar a capacidade cognitiva } \\
\text { global }\end{array}$ & $\begin{array}{c}\text { Mini Exame do Estado } \\
\text { Mental }\end{array}$ & $\begin{array}{c}\text { MCHUGH, 1975; } \\
\text { BERTOLUCCI } \text { et al., } \\
1994 ; \text { BRUCKI } \text { et al., } \\
\text { 2003) }\end{array}$ \\
\hline $\begin{array}{c}\text { Bloco 04 - Informações } \\
\text { Sociodemográficas do } \\
\text { Idoso }\end{array}$ & Estado civil e escolaridade & Ficha Diagnóstica & $\begin{array}{c}\text { Desenvolvida pelo } \\
\text { LAGER/CEFID/UDESC }\end{array}$ \\
\hline $\begin{array}{c}\text { Bloco 05 - Atividades } \\
\text { no Lazer no Passado e } \\
\text { Presente do Idoso }\end{array}$ & $\begin{array}{c}\text { Descrever as atividades no lazer } \\
\text { na infância, infância, vida adulta, } \\
\text { velhice e fase atual }\end{array}$ & $\begin{array}{c}\text { Questionário com } \\
\text { questões abertas sobre } \\
\text { as atividades no lazer }\end{array}$ & $\begin{array}{c}\text { LAGER/CEFID/UDESC } \\
\text { Desenvolvido pelo }\end{array}$ \\
\hline
\end{tabular}

Fonte: Elaborado pelos autores, 2016.

Os Blocos 01 e 04 foram respondidos pelo cuidador principal. Os centenários responderam às questões do Bloco 03, que consiste na aplicação do Mini Exame de Estado Mental - MEEM (FOLSTEIN; FOLSTEIN; MCHUGH, 1975; BERTOLUCCI 
et al., 1994), devendo atingir o ponto de corte, de acordo com a escolaridade (BRUCKI et al., 2003) para responder às questões do Bloco 05.

Com relação ao Bloco 05, as atividades no lazer nas diferentes fases da vida foram distribuídas em seis categorias propostas pela literatura (DUMAZEDIER, 1973; CAMARGO, 1998), conforme está apresentado no (QUADRO 2).

Quadro 2 - Categorias das atividades no lazer.

\begin{tabular}{|c|c|}
\hline $\begin{array}{c}\text { ATIVIDADES NO } \\
\text { LAZER }\end{array}$ & DESCRIÇÃO \\
\hline Artísticas & É a experiência estética ocasionada por imagens, emoções e sentimentos. \\
\hline Físicas & $\begin{array}{c}\text { Incluem os esportes em geral, a dança, a caminhada, a pesca, a ginástica, os } \\
\text { passeios, dentre outras atividades em que prevalece o movimento ou o } \\
\text { exercício físico. }\end{array}$ \\
\hline Intelectuais & Tem ênfase no raciocínio \\
\hline Manuais & $\begin{array}{c}\text { Concentra na manipulação, tanto para transformar objetos ou materiais, } \\
\text { como para lidar com a natureza. Destacam-se as atividades como } \\
\text { jardinagem, costura, marcenaria, consertos, reparos e culinária. }\end{array}$ \\
\hline Sociais & $\begin{array}{c}\text { Incluem as atividades de engajamento social, percebidas como importantes } \\
\text { conquistas do ser humano, atreladas à satisfação das necessidades } \\
\text { individuais ou sociais, como exemplos, reuniões e associações voluntárias } \\
\text { diversas, encontro e relacionamentos em bares, cafés, bailes. }\end{array}$ \\
\hline Turísticas & Busca pelo contato com novas paisagens, pessoas e costumes. \\
\hline
\end{tabular}

Fonte: Elaborado pelos autores, 2016.

A coleta de dados ocorreu em duas ocasiões. A primeira consistiu em um contato telefônico, ou pessoalmente, com o cuidador e/ou com o centenário. Nesta ocasião, foi realizado o convite para participação da pesquisa e foram explicados os objetivos do estudo, a sua importância, as etapas, a forma de aplicação dos instrumentos, o sigilo de identidade e o retorno dos dados da pesquisa. Após o aceite dos envolvidos, foi agendada a visita para o início da coleta de dados.

Na segunda ocasião foi assinado o Termo de Consentimento Livre e Esclarecido e foram aplicados os questionários ao centenário, em forma de entrevista gravada e, ao cuidador, em forma de entrevista. A fim de garantir o sigilo da identidade e os 
princípios éticos de pesquisa, os fragmentos dos depoimentos são identificados por nomes fictícios.

Utilizou-se um gravador digital para gravar as questões abertas do Bloco 05, para a análise dos dados foi empregada a análise de conteúdo temática a partir dos depoimentos transcritos e realização da análise de conteúdo temática, que prevê três etapas principais seguindo os passos pré-análise, exploração do material e tratamento dos resultados (MINAYO, 2008). As categorias foram definidas a partir das atividades (artísticas, físicas, intelectuais, manuais, sociais e turísticas).

\section{Resultados e Discussões}

Os dados sociodemográficos estão apresentados na (TABELA 1). Os idosos do estudo eram, em sua maioria, viúvos e do sexo feminino e apenas dois idosos frequentaram a escola.

Tabela 1 - Distribuição de frequência das características sociodemográficas.

\begin{tabular}{|c|c|}
\hline $\begin{array}{c}\text { CARACTERÍSTICAS } \\
\text { SOCIODEMOGRÁFICAS }\end{array}$ & $\mathbf{F}$ \\
\hline $\begin{array}{l}\text { Estado Civil } \\
\text { Solteiro (a) } \\
\text { Viúvo (a) } \\
\end{array}$ & $\begin{array}{l}01 \\
05\end{array}$ \\
\hline $\begin{array}{l}\text { Sexo } \\
\\
\text { Feminino } \\
\text { Masculino }\end{array}$ & $\begin{array}{l}04 \\
02\end{array}$ \\
\hline $\begin{array}{l}\text { Estudou na Escola } \\
\text { Sim } \\
\text { Não }\end{array}$ & $\begin{array}{l}02 \\
04\end{array}$ \\
\hline
\end{tabular}

Fonte: Elaborada pelos autores, 2016.

A partir dos resultados, observa-se a prevalência de mulheres centenárias, à semelhança de outros estudos no mesmo âmbito, o que indica haver um número maior de mulheres do que de homens nessa população (CHO; MARTIN; POON, 2012; 
WONG et al., 2014). Esse fenômeno conhecido como feminização da velhice vem acompanhando o envelhecimento populacional no mundo, sendo mais evidente nos estratos etários mais velhos (CAMARANO; KANSO, 2011). Ao se reportarem a esse fenômeno, as autoras colocam que mulheres idosas experimentam maior probabilidade de ficarem viúvas, o que pode ser observado nos dados deste estudo e também é corroborado por outros estudos com populações de idosos centenários, os quais mostram uma predominância do estado civil viúvo para mulheres (CHO; MARTIN; POON, 2012; TIGANI et al., 2012).

Ao analisar a escolarização, torna-se importante salientar que, apesar de somente dois idosos terem estudado na escola, esta tinha um papel fundamental na sua vida, especialmente na socialização, o que foi mencionado por meio de relatos sobre a realização de atividades no lazer na escola. A baixa escolaridade observada nesse estudo vem ao encontro do estudo realizado na Grécia, o qual demostrou que $42 \%$ dos centenários eram analfabetos (TIGANI et al., 2012). Camarano (2004) atribui esse fato à falta de acesso à escolaridade no início do século XX e acrescenta que, na população brasileira, tem-se observado acessibilidade aos serviços como a educação, a partir da segunda metade dos anos 1950.

A respeito das atividades no lazer nas diferentes fases da vida, as mais reportadas pelos idosos centenários foram agrupadas em seis categorias propostas pela literatura (DUMAZEDIER, 1973; CAMARGO, 1998), conforme resultado apresentado na (TABELA 2). Estas atividades serão mencionadas conforme os depoimentos dos idosos, para a compreensão dos tipos de atividades no lazer que os mesmos realizaram durante o curso de vida. 
Tabela 2 - Frequência dos centenários que realizaram as atividades no lazer nas diferentes fases da vida. $(n=6)$

\begin{tabular}{|l|c|c|c|c|}
\hline $\begin{array}{l}\text { Categorias de atividades } \\
\text { no lazer }\end{array}$ & Infância & Adolescência & Adulta & Velhice/Atual \\
\hline Artísticas & 03 & - & 01 & - \\
\hline Físicas & 05 & 01 & - & 01 \\
\hline Intelectuais & - & - & - & - \\
\hline Manuais & 06 & 02 & 05 & 01 \\
\hline Sociais & 06 & 05 & 03 & 03 \\
\hline Turísticas & 01 & - & & - \\
\hline
\end{tabular}

Fonte: Elaborada pelos autores, 2016.

Constatou-se que, com o avançar da idade, as atividades no lazer foram atenuando. Esse fato é corroborado pelo estudo de Almeida et al. (2005), o qual verificou que, com o passar do tempo, a prática de atividades no lazer diminui, devido a diversos fatores que interferem nessa prática, como as condições socioeconômicas, escolaridade, falta de entusiasmo e limitações físicas que dificultam mobilidade, visão e audição. Embora não estivessem previstas observações na coleta de dados deste estudo, ao longo dos contatos e das aproximações com os centenários, foi possível perceber a satisfação e a alegria ao lembrarem e ao tecerem comentários sobre as atividades no lazer que realizavam no período da infância.

Na fase da infância dos centenários destacam-se as atividades no lazer manuais, sociais e físicas, as quais devem ser entendidas a partir da predominância em cada uma delas, não estando, portanto, isoladas, na medida em que se inter-relacionam. Nas atividades manuais, as mais citadas envolviam o desenvolvimento da motricidade fina, as quais criavam um universo lúdico, no qual se tentava arremedar seus pais, como relata Afrânia: “[...] brincávamos muitas vezes no fundo do quintal de cozinha, eu e minhas irmãs [...] A minha mãe mandava comida lá de cima e nós brincávamos de panelinha de barro [...] A comida às vezes ia fora porque não prestava”, e Ananda, que 
descreve detalhes, demonstrando com suas mãos, uma das brincadeiras preferidas: "Bilboquê, como era que era aquela coisa [...] de madeira, tinha uma cordinha entre as peças e tinha que cair aqui dentro [...]". Também Normélio conta que, entre as brincadeiras preferidas, "[...] gostava mais de fazer casinha e fazer lavoura".

Com relação às atividades sociais, era comum o envolvimento com seus familiares em eventos religiosos e culturais, como destacam Normélio: “[...] na igreja ia, todo dia, era pertinho de casa", e Ananda, sobre ir ao teatro com o pai: "Tu acreditas que o Teatro Álvaro de Carvalho ficava perto, então tinha carro, nos saímos da nossa casa, era como aqui ate o paredão [...] para ir de carro ao teatro [...]”. Essas atividades sociais também eram realizadas com outras pessoas de sua geração, como descreve Normélio: “[...] brincava com os amigos, tinha bastante criança” e conforme relata Edmundo: “[...] brincadeiras de roda [...] cantávamos cantigas, éramos quinze irmãos, quatro meninas e onze meninos, elas brincavam do jeito delas, de boneca e nós jogávamos bola naqueles campos de pastagem de gado”.

Nas atividades físicas, as atividades no lazer mais citadas envolviam movimento, como jogar bola, brincadeiras de roda, balanço, pular corda e soltar pipa. Normélio conta como era o jogo: “Jogava, jogava bola. Bola não tinha, era calha, pegava uma pedra jogava longe para derrubar, tipo bolão" e Afrânia refere-se ao balanço como brincadeira preferida, “[...] o nosso brinquedo era balanço [...], os rapazes mais velhos puxavam a corda para começar o balanço [...], davam um empurrão que não parava mais". Ecilda relata sua habilidade nas brincadeiras: "Então até duas cordas, uma pra lá e outra pra cá [...] hoje não dá nenhuma (risos). Gostava de soltar pandorga! Soltar pandorga, coisa boa". 
As atividades artísticas concentraram-se apenas nas musicais, conforme a fala de Ecilda: "Na minha família todos aprenderam piano, mas ninguém chegou a minha altura (risos) [...], meu irmão mais velho tocava flauta e tinha um amigo que tocava violino, e então às vezes, à noite, nós reuníamos, eu no piano, meu irmão na flauta e outro no violino $[\ldots]$ mas naquela época. Hoje se tocar piano, toca todo mundo pra rua [...], eu vejo um piano e fico bem atenta, relembrando do passado".

É importante destacar que os idosos centenários se remeteram, em suas entrevistas, às brincadeiras de forma geral, as quais, por sua vez, não se diferem das brincadeiras realizadas nos estudos encontrados com idosos mais novos. Para Pontes e Magalhães (2003), algumas brincadeiras são passadas entre as gerações. Percebe-se, ainda, que as brincadeiras tradicionais e as populares entre os idosos centenários e os idosos mais novos são geralmente realizadas na rua. Característica diferente das crianças em geral, as quais, na atualidade, passam grande parte do tempo brincando dentro de casa, com oportunidades restritas para desfrutarem o lazer ao ar livre, seja por falta de tempo dos pais em acompanhá-las, por questões de segurança ou, até mesmo, por opção, entre outras condicionantes.

Um fato interessante é que nenhum idoso relatou brincadeiras individuais, todos brincavam com amigos, vizinhos e familiares, demonstrando o benefício da atividade para a socialização dos indivíduos. Este fato também é observado no estudo com idosas entre 51 a 91 anos nascidas e crescidas em Belo Horizonte (MG), o qual identificou brincadeiras na infância como cantiga de roda, passa-anel, chicotinho queimado, esconde-esconde, pega-pega 10, casinha e fazer comidinha (JINZENJI; GALVÃO e SILVA, 2012). Outra pesquisa com dez idosos (idade entre 64 a 85 anos) verificou 
brincadeiras em grupo, como corrida, pular corda, futebol com bola feita de bexiga de animais, bocha de pedra, amarelinha e bonecas (FERNANDES, 2011).

A variedade das brincadeiras e a possibilidade de brincar com outras pessoas parece ser um diferencial no discurso dos idosos centenários deste estudo e dos supracitados, uma vez que, na atualidade, pode-se observar o quanto o universo infantil é solitário, restrito, na maioria das vezes, as brincadeiras no contexto doméstico, na companhia de recursos tecnológicos, como televisão, computador e videogame. Esta realidade tem sido retratada e investigada por vários autores e denota uma ressignificação do brincar na vida contemporânea, a qual demanda diferentes olhares para a compreensão de suas ressonâncias no próprio significado de lazer, educação e felicidade dos envolvidos (TONUCCI, 2005; SINGER, D. G.; SINGER, 2007; VEEN; WRAKKING, 2011).

Os idosos investigados ainda ressaltaram que as brincadeiras aconteciam somente depois das responsabilidades individuais. Alguns trabalhavam mesmo na infância, e podiam brincar somente depois do trabalho; outros brincavam somente no final de semana. Ecilda destacou, sobre o tempo para brincar: "Sábado e domingo de tarde, e depois ainda que arrumasse a louça do café, é que ia brincar” e Afrânia contou: “Nos domingos nós estávamos no serviço, só quando tinha novena de noite que mamãe nos levava". Observa-se que a categoria trabalho se faz presente desde a infância na vida dos centenários, diminuindo a frequência de atividades laborais somente na velhice, o que pode ser atribuído ao declínio da capacidade funcional dos idosos (CAMARANO; KANSO, 2011).

Ao apresentar a fase da adolescência, a qual foi versada pelos centenários como juventude, observa-se uma evidência para atividades sociais, como ir a bailes. Ao relatar 
o contexto dos bailes, os centenários se emocionam e descrevem os momentos como se estivessem revivendo-os, conforme a fala de Normélio: “Eu não perdia baile [...] dançava, namorava, brigava" e Edmundo: "Eu comecei ir a baile, com 15 anos [...] Ah ia, gostava, encostar nas gurias, que coisa boa!! Ah elas gostavam também. Ah adorava, adorava, adorava". Também Oneide descreve suas lembranças sobre os bailes: "Ih, nem fale $[. .$.$] eu comecei ir a baile com quinze anos [...] quinze anos, minha madrinha levava$ as filhas dela e eu ia junto, mas até lá eu não gostava, não queria, não dançava. Depois que eu peguei gosto, não saía do baile [...]”.

$\mathrm{Na}$ fase adulta foram relatadas outras atividades sociais, como eventos religiosos, culturais e sociais, como menciona Edmundo: "Sempre fui católico, sempre [...] mas eu visitava todas as outras religiões, todas, as espíritas, as protestantes. No Rio tem muito, o protestantismo no Rio é muito grande, tem igrejas bonitas sabe? Eu ia todas essas [...]”. Afrânia relata que conheceu muitos lugares junto das famílias que trabalhava: "Viajava, mas a trabalho para [...] a patroa e o patrão, para onde eles iam eu tinha que ir junto, a cozinheira ia junto, eles não gostavam de comer no hotel [...] toda vida foram ricos e eu fui pobre, mas [...] toda vida [...] aproveitava com eles, aproveitava a comida e viajava pro Rio, era pra Niterói e pra Ilha do Governador".

Com relação à fase da velhice e atual, observa-se a manutenção das atividades turísticas e sociais, como conta Ananda: “[...] todo ano eu fazia uma viagem, às vezes até duas [...] eu viajei muito, tu sabes que eu conheço todos os países do mundo, todos os continentes, e comecei viajar depois dos 60 anos. Eu ia com a minha filha Vera. Primeiro eu ia sozinha, ia com a excursão para São Paulo. Depois a Vera começou a sair comigo, e uma sobrinha também. Nós íamos todo ano, cada ano nós fazíamos uma viagem grande, percorríamos diversos países. Eu gosto muito da Itália, é um pais muito 
alegre. Viajava por tudo, de avião, de navio, por tudo [...]. A viagem mais longa foi daqui do Brasil, não sei se para China ou Japão, foram 12 horas”. Sobre a fase atual, Ananda conta que se reúne semanalmente com as amigas para conversar: "Toda quintafeira é reunião. Mas agora, desde dezembro até abril, não funciona. Depois começa outra vez. São mais ou menos catorze amigas [...] Comemos um lanche”. Dona Oneide também relembra-se de suas viagens: "Ah eu gosto de viajar, eu fiz viagem pra Porto Alegre [...] eu fiz uma porção de viagens a pouco, só pra porto alegre foi quatro vezes. Fui pra são Paulo, duas vezes, eu ainda fui de ônibus, mas depois dai pra cá, faz 10 anos que não fui pra São Paulo". Também Ecilda relata suas atividades no lazer atuais: "Esses dias eu fui ao aniversário na casa da minha sobrinha, lá tem dois ou três casais, conversaram, e eu estava de lado escutando, uma delas me abraçou e me beijou, eu sou fulana de tal, eu fui sua aluna, a senhora era muito brava [...]. Perguntei a ela: Você não aprendeu? Ela respondeu: sim, aprendi muito [...] Então respondi, está aí o resultado”.

Ao conversar sobre as atividades no lazer que desenvolve atualmente, Ecilda fala: "[...] gosto muito de ir ao centro, ao mercado público, no comercio [...] mas se eu saio, saio de carro eles me levam [...] Mas eu gosto, mas não posso mais ir sozinha [...] Aquele senhor que estava aqui, que está me atendendo", se referindo ao sobrinho que estava lhe visitando, e continua falando sobre o apoio que tem hoje para suas atividades: "Tudo tem jeito. Tem três pessoas que me cuidam. Tem uma por dia, uma vai pra cozinha e uma a noite, não posso ficar sozinha".

Pode-se constatar a vivência de diversas atividades no lazer pelos centenários nas diferentes fases da vida, o que pode ter contribuído para a qualidade de vida atual, bem como a manutenção de algumas atividades nesta fase da velhice. De acordo com Everard et al. (2000), a manutenção de atividades no lazer foi associada com melhoras 
da saúde física e atividades estimulantes e sociais protegem contra a demência e, consequentemente, melhora a interação social dos idosos (WANG et al., 2002). As atividades no lazer ainda diminuem o risco de mortalidade (PAGANINI-HILL; KAWAS; CORRAD, 2011), preservam o estado cognitivo (ZHANG, 2006) e proporcionam engajamento social (GLASS et al., 1999).

Estes estudos supramencionados abordam as atividades no lazer realizadas na velhice. No Brasil, o número de investigações sobre centenários e atividades no lazer, realizadas durante as diferentes fases da vida, é escasso. Tais estudos são importantes porque a manutenção de um estilo de vida ativo por meio de atividades no lazer durante o curso da vida traz benefícios como melhoria do bem-estar, da qualidade de vida, da socialização entre outros.

Contraditoriamente, sabe-se que, com a chegada da aposentadoria e consequente redução das obrigações deveria ser, conforme apresenta Marcellino (2008), o "paraíso do lazer", período adequado para o aproveitamento da vida. No entanto, ainda que o lazer seja um direito garantido pela Constituição Brasileira (BRASIL, 1988), não é o que se nota na contemporaneidade. Fatores econômicos, como a diminuição dos ganhos mensais; questões sociais, como a supervalorização do trabalho; problemas de saúde e locomoção, além de vários estereótipos são apresentados, por Marcellino (2008), como limitadores para a participação dos idosos no lazer. No caso, em particular, dos centenários investigados neste estudo, a situação se agrava ainda mais porque a maioria deles necessita do apoio familiar e do cuidador, o qual, nem sempre está disposto (ou é competente para) auxiliar no enfrentamento de tais obstáculos. 


\section{Considerações Finais}

Foi possível constatar com este estudo que as atividades no lazer dos idosos centenários foram diminuindo ao longo dos anos, e que as atividades sociais, de certa forma, permaneceram durante boa parte de suas vidas e, na velhice/fase atual, observase a ocorrência de atividades turísticas, sociais e intelectuais.

Os resultados desse estudo possibilitaram refletir sobre as atividades no lazer no curso da vida dos centenários e, com isto, vislumbrar a necessidade de intervenções no lazer no ambiente domiciliar. Ressalta-se a importância da formação e capacitação de recursos humanos, especialmente o cuidador familiar, para atuarem com esta população, de maneira que propiciem o estímulo ao movimento nas residências e fora dela.

Neste processo, acredita-se na necessidade de mais reflexões e diálogos com as políticas públicas, no sentido de assegurar, em um contexto mais amplo de coparticipação com comunidades e instituições envolvidas, mais oportunidades de lazer para os centenários, a partir da manutenção de atividades que tenham significado e valor emocional para os mesmos.

Estudos futuros para a ampliação dos conhecimentos acerca dos fatores que podem influenciar na longevidade, apesar das limitações físicas e funcionais que os centenários possam ter, são de suma importância.

\section{REFERÊNCIAS}

ALMEIDA, M. et al. Atividades de lazer entre idosos. Revista Baiana de Saúde Pública, Salvador, v. 29, n. 2, p.339-352, 2005.

BENETTI, M. Z. Estilo de vida de idosos centenários de Florianópolis, SC. 2011. Dissertação (Mestrado em Ciências do Movimento Humano) - Universidade do Estado de Santa Catarina, 2011. 
BERTOLUCCI, P. H. F. et al. O miniexame do estado mental em uma população geral. Impacto da escolaridade. Arquivos de Neuropsiquiatria, São Paulo, n. 52, p. 1-7, 1994.

BRASIL. Constituição (1988). Constituição da República Federativa do Brasil. Brasília, DF: Senado Federal; 1988. Disponível em: http://www.presidencia.gov.br/legislacao .

BRUCKI, S. M. D. et al. Sugestões para o uso do mini-exame do estado mental no Brasil. Arquivos de Neuropsiquiatria, São Paulo, v. 61, n. 3B, p. 777-81, 2003.

CAMARANO, A. A. Os Novos Idosos Brasileiros: Muito Além dos 60?. Rio de Janeiro: IPEA, 2004. 604 p.

CAMARANO, A. A.; KANSO, S. Envelhecimento da população brasileira, uma contribuição demográfica. In: FREITAS, V.; PY, L. Tratado de Geriatria e Gerontologia. 3. ed. Rio de Janeiro: Guanabara Koogan, 2011. p. 58-73.

CAMARGO, L. O. L. Educação para o lazer. São Paulo: Moderna, 1998.

CHO, J.; MARTIN, P.; POON, L. W. The older they are, the less successful they become? Findings from the Georgia Centenarian Study. Journal of aging research, New York, 2012.

DIAS, E. G.; DUARTE, Y. A. O.; LEBRÃO, M. L. Efeitos longitudinais das atividades avançadas de vida diária em idosos: implicações para a reabilitação gerontológica. $\mathbf{O}$ Mundo da Saúde, São Paulo, v. 34, n. 2, p. 258-267, 2010.

DUMAZEDIER, J. Lazer e cultura popular. São Paulo: Perspectiva, 1973.

EVERARD, K.M. et al. Relationship of activity and social support to the functional health of older adults. The Journals of Gerontology Series B: Psychological Sciences and Social Sciences, Washington, v. 55, n.4, p.208-212, 2000.

FERNANDES, H. F. S. Os descendentes italianos e sua influência nas brincadeiras e jogos na cidade de Nova Veneza - SC. 2001. Trabalho de Conclusão de Curso (Graduação em Educação Física - Licenciatura) - Universidade do Extremo Sul Catarinense, 2011.

FOLSTEIN, M. F.; FOLSTEIN, S. E.; MCHUGH, P. R. "Mini-mental state". A practical method for grading the cognitive state of patients for the clinician. Journal of Psychiatric Research, Kidlington, v. 12, n. 3. p. 189-198, 1975.

GLASS, T. A. et al. Population based study of social and productive activities as predictors of survival among elderly Americans. British Medical Journal, London, v. 319, p. 478-483, 1999.

GOMES, C. L. Lazer: necessidade humana e dimensão da cultura. Revista Brasileira de Estudos do Lazer, Belo Horizonte, v. 1, n. 1, p. 3-20, 2014. 
IBGE. INSTITUTO BRASILEIRO DE GEOGRAFIA E ESTATÍSTICA. Síntese de indicadores sociais - Uma análise das condições de vida da população brasileira. Rio de Janeiro: 2010.2 Disponível em: http://www.ibge.gov.br/cidadesat/topwindow.htm?1> . Acesso em: 06 nov. 2013.

JANNEY, C. A. et al. Longitudinal physical activity changes in older men in the osteoporotic fractures in men study. Journal of the American Geriatrics Society, Hoboken, v. 58, n. 6, p. 1128-1133, 2010.

JINZENJI, M. Y.; GALVÃO, A. M.; SILVA, S. A. Memórias sobre a infância no meio rural: a escola e os outros espaços de sociabilidade (Minas Gerais - Brasil, 1920-1950). Revista Portuguesa de Educação, Monte, v. 25, n. 2, 2012.

LAGER (Universidade do Estado de Santa Catarina). Laboratório de Gerontologia. Protocolo de Avaliação Multidimensional do Idoso Centenário. 2015. Disponível em: http://www.cefid.udesc.br/arquivos/id submenu/2017/protocolo geral do idoso cente nario.pdf. Acesso em: 31 maio 2015.

LONGARAI, R. Hábitos pregressos de atividade física em centenários de Porto Alegre. 2005 (Mestrado em Gerontologia Biomédica). Programa de Pós Graduação em Biomedicina. Porto Alegre: Pontifícia Universidade Católica do Rio Grande do Sul, 2005.

MARCELLINO, N. C. Lazer e cultura: algumas aproximações. In: MARCELLINO, N. C. Lazer e cultura. Campinas: Alínea, 2007. p. 9-30.

. Lazer e Humanização. 9. ed. Campinas: Papirus, 2008.

MINAYO, M. C. S. O desafio do conhecimento. 11 ed. São Paulo: Hucitec, 2008.

PAGANINI-HILL, A. P.; KAWAS, C. H.; CORRADA, M. M. Activities and Mortality in the Elderly: The Leisure World Cohort Study. The Journals of Gerontology Series A: Biological Sciences and Medical Sciences, Washington, v. 66, n. 5, p. 559-567, 2011.

PONTES, F.; MAGALHÃES, C. A Transmissão da Cultura da Brincadeira: algumas possibilidades de investigação. Psicologia: Reflexão e Crítica, v.16, n. 2, p. 117-124, 2003.

SANTOS, P. et al. Atividades no lazer e qualidade de vida de idosos de um programa de extensão universitária em Florianópolis (SC). Revista Brasileira de Atividade Física e Saúde, Pelotas, v. 19, n. 4, p. 494-503, 2014.

SCARMEAS, N. et al. Influence of leisure activity on the incidence of Alzheimer's. Neurology, Philadelphia, v. 57, n. 12, p. 2236-2242, 2001.

SCHRADER, S. Centenarians' Views on Long Life and Nursing Home Living. Journal of the American Medical Directors Association, New York, v. 9, p. 45-50, 2008. 
SINGER, D. G.; SINGER, J. T. Imaginação e jogos na era eletrônica. Porto Alegre: Artmed, 2007.

STREIT, I. A. Idosos centenários: nível de atividade física e hábitos de lazer. 2013 (Dissertação de mestrado em Ciências do Movimento Humano). Programa de Pósgraduação em Ciências do Movimento Humano, UDESC, 2013.

TIGANI, X. et al. Self-rated health in centenarians: A nation-wide cross-sectional Greek study. Archives of gerontology and geriatrics, Clare, v. 54, n. 3, p. e342-e348, 2012 .

TONUCCI, Francesco. Quando as crianças dizem: agora chega! Porto Alegre: ARTMED, 2005.

VEEN, W.; WRAKKING, B. Educação na era digital. Pátio Educação Infantil, Porto Alegre, v.19, n. 28, p. 4-7, jul./set. 2011.

UNITED NATIONS (Org.). Word urbanization prospects, the 2014 revision. 2015. Disponível em: http://esa.un.org/unpd/wup/CD-ROM/ . Acesso em: 12 dez. 2015.

WANG, H. X. et al. Late Life Leisure Activities and Risk of Cognitive Decline. The Journals of Gerontology Series A: Biological Sciences and Medical Sciences, Washington, v. 68, n. 2, p. 205-213, 2013.

WANG, H. X. et al. Late-life engagement in social and leisure activities is associated with a decreased risk of dementia: a longitudinal study from the Kungsholmen project. American Journal of Epidemiology, Cary, v. 155, p.1081-1087, 2002.

WHO. World Health Organization. World report on Ageing and Health. 2015. Disponível em: http://www.who.int/kobe_centre/mediacentre/world_report_on_ageing_and_health_eng. pdf. Acesso em: 12 dez. 2015.

WONG, W. P. et al. The well-being of community-dwelling near-centenarians and centenarians in Hong Kong a qualitative study. BMC Geriatrics, London, v. 14, p. 1-8, 2014.

ZHANG, Z. Gender Differentials in Cognitive Impairment and Decline of the Oldest Old in China. The Journals of Gerontology Series B: Psychological Sciences and Social Sciences, Washington, v. 61, n. 2, p. 107-115, 2006.

\section{Endereço dos Autores:}

Maíra Naman

Rua Uruguai, 458 - Centro

Itajaí - SC - 88.302-202

Endereço Eletrônico: mairanaman@hotmail.com 
Maíra Naman, Inês Amanda Streit,

Artur R. Fortunato, Alcyane Marinho e

Giovana Z. Mazo

Inês Amanda Streit

Rua São Cristóvão, 438, Bairro Coqueiros

Florianópolis - SC - 88.080-320

Endereço Eletrônico: inesamanda@gmail.com

Artur Rodrigues Fortunato

Servidão Augusto Schimidt, 227, Costeira do Pirajubae

Florianópolis - SC - 88.080-320

Endereço Eletrônico: artur.rfortunato@gmail.com

Alcyane Marinho

Rua Vereador Ramon Filomeno, 357

apto. 100, Torre 1, Parque São Jorge

Florianópolis - SC - 88.034-495

Endereço Eletrônico: alcyane.marinho@hotmail.com

Giovana Zarpellon Mazo

Avenida Buriti, 680, Itacurubi

Florianópolis - SC - 88.034-500

Endereço Eletrônico: giovana.mazo@udesc.br 